\title{
CC Pressure Test
}

\author{
3740.214-EN-259
}

\author{
July 12,1990
}

K. Dixon

Checked by 


\section{Vessel Status Prior to Testing}

The inner vessel heads including bypass and beam tubes had just been welded into place and dye penetrant checked. The vacuum heads were not on at this time but the vacuum shell was on covering the piping penetrating into the inner vessel. Signal boxes with all feed through boards, the instrumentation box, and high voltage boxes were all installed with their pump outs capped. All $1 / 4^{\prime \prime}$ instrumentation lines were terminated at their respective shutoff valves.

All vacuum piping used for pumping down the inner vessel was isolated using o-ring sealed blind flanges. PV215A (VAT Series 12), the 4" VRC gate valve isolating the cyropump, and the rupture disk had to be removed and replaced with blind flanges before pressurizing due to their pressure limitations. Stresses in plates used as blind flanges were checked using Code calcualtions. Before the $\mathrm{CC}$ test, vacuum style blanks and clamps were hydrostatically pressure tested to $150 \%$ of the maximum test pressure, 60 psig.

The Code inspector and Research Division Safety had all given their approval to the test pressure and procedure prior to filling the vessel with argon.

\section{Test Results}

The test was a major success. Based on the lack of any distinguishable pressure drop indicated on the pressure gages, the vessel appeared to be structurally sound throughout the duration of the test (approx. $3 \mathrm{hrs}$.). A major leak in the instrumentation tubing was discovered at half of the maximum test pressure and was quickly isolated by crimping and capping with a compression fitting.

There were some slight deviations in the actual procedure used (see attachments). The 44 psig relief valve located just outside the clearroom had to be capped urtil the pressure in the vessel indicated 38 psi. This was to allow higher supply pressures and hence, higher flows through the pressurizing line. Also, in order to get pressure readings at the cryostat without exposing any personnel to the potentially dangerous stored energy near the maximum test pressure, a camera was installed at the top of the vessel to view the indicator mounted there. The monitor was viewed at the ante room adjacent to the cleanroom.

The holding pressure of $32 \mathrm{psig}$ ( $4 / 5$ of the maximum test pressure) was only maintained for about 20 minutes instead of the half hour recommendation in the procedure. We felt that this was sufficient time to Snoop test and perform the pressure drop test.

After the test was completed, the inspector for CBI Na-Con and the Research Divison Safety Officer signed all of required documentation. 
From: FNAL::MULHOLLAND 6-JUL-1990 12:47:23.92

To: $\quad$ KDIXON

CC: MULHOLLAND

Subj: As you requested.

$7 / 5 / 90$ Final version

PTest is the CC Pressure Test

This note describes the rationale for the test pressure of the completed CC calorimeter Pressure Test, provides a detailed operating procedure, and a Safety documentation and interface outline.

\section{TEST PRESSURE}

The CC vessel was pneumatically pressure tested to 50 psig at the fabricator, LOX in Delphi, Indiana. The test pressure was determined as follows,

\begin{tabular}{llll} 
MAWP & & \\
& + Vacuum & 15.0 & psig \\
& LAr head & 10.73 & psig \\
\hline Sum & 39.73 & psig \\
Test Pressure & 1.25 (Sum) & 49.66 & psig
\end{tabular}

Removal and replacement of the heads and the installation of the nozzle extensions ( 4 signal boxes, 2 high voltage boxes, 1 instrumentation box, cold valve, and other appurtenances) are considered justification to repeat the pressure test on the completed calorimeter.

The vessel's multiple extensions will never see an operational pressure more than 15 psig, i.e. they don't see the vacuum because they are outside the vacuum envelope and they don't see the head (or at least any significant portion thereof) pressure. To Pneumatically test the vessel to $125 \%$ of the sum of the MAWP and liquid head, tests the upper portions of the vessel to 166\%, and the nozzle extensions and their parts to $333 \%$, of the respective maximum al lowable working pressures.

The solution to the upper and lower vessel disparity is to fill the vessel with liquid for the test, and the solution to the vacuum loading is to install the vacuum jacket before the pressure test. Unfortunately, the vessel can not be filled with liquid without compromising the integrity of the calorimeter modules. The vacuum vessel can not reasonably be put in place (welded) to provide the vacuum loading, if the final leak check is to follow the pressure test. The latter is the accepted practice for obvious reasons.

The usual accomodation is to relinquish the head pressure requirement. That works well on high pressure vesssels, those with small heights (horizontal vessels), and/or those with low density liquids (Helium) because the effect is a small fraction of the maximum load test pressure. The resolution for low pressure, tall, and high density liquid vessels (our situation) is more difficult, and not as obvious. The compromise proposed in this case, and by extension for the EC's, is,

\begin{tabular}{|c|c|c|c|}
\hline Source & & & Remarks \\
\hline Vacuum & $\begin{array}{l}15 \\
14.36\end{array}$ & $\begin{array}{l}\text { psig } \\
\text { psig }\end{array}$ & $\begin{array}{l}\text { Relief is } 13 \text { psig } \\
707^{\prime} \text { above sea level }\end{array}$ \\
\hline
\end{tabular}




$\begin{array}{llll} & \text { Head LAr } & 10.0 & \text { psig } \\ & \text { Sum } & 39.36 & \text { psig } \\ \text { Test Pressure } & \text { ca. Sum } & 40.0 & \text { psig }\end{array}$

In that way the upper pressure is limited to $136 \%$ of its maximum allowable value, the lower portion is tested to $100 \%$ of its maximum allowable pressure plus head, and the nozzle extensions pressures are limited to $267 \%$ of their maximum allowable pressures. Note that there are extension items that will necessarily, be removed for the pressure test and later reinstalled (see the Procedures, below), and others that must remain (e.g. signal boxes). GAr will be used as the pressurizing gas because it is the operating fluid.

Conclusion

The pneumatic test pressure will be 40.0 psig, GAr, as the best compromise among competing requirements.

\section{PROCEDURE}

General

Provide a source (actual calculated requirement is $1840 \mathrm{scft}$, but provide 5000 scf minimum) of GAr through a LP regulator and a line fitted with a $110 \%$ test pressure relief valve of larger flow capacity than the LP regulator. Provide two test gauges, one on an independent cryostat port, the other on the pressurizing line. A shutoff and then a vent valve should be located just downstream of the LP regulator and relief. All of the equipment, except for the cryostat pressure gage, must be located out of the line of sight of the vessel and behind a barrier of sufficient strength to assure shrapnel, that might be created in a vessel failure, can not reasonably be expected to injure the test operators at the pressure test stand.

The test will be performed insitu, in the clean room of the $D$ Zero Assembly building, and must be done with the building empty of all personnel not essential to the test as the vessel is pressurized. All entry doors should be equipped with a sign warning of the test and clearly stating "Keep Dut". One member of the test team should make it his task to assure stray spectators do not find their way to the test area. See the last section on Safety participation and abide by those constraints as well. Complete any necessary or desireable communication with CBI NACON or their Code inspector before conducting the pressure test.

\section{Actual Procedure}

1. Assure that the two immediately preceeding paragraphs are read, understood, and all actions taken and completed.

2. The vessel should be inspected to assure it is properly closed and does not exhibit any irregularities that might preclude a successful test.

$2 a$. The following extension items must be removed and their nozzles suitablly capped before the pressure test;
A. The pump and purge valve, it has a one atmosphere rating.
B. The 18 psig Rupture disk assembly.
C. The 13 psig Relief valve assembly.
D. Vulnerable (over ranged) Pressure Transmitters. 


\section{E. All vacuum pumping appendages not Test Pressure rated.}

3. The pressure in the vessel (ca. $660 \mathrm{cft}$ ) shall be gradually increased with GAr to not more than one-half of the test pressure. The agreement of the test station and vessel presssure gages should be verified or corrected as required. Thereafter, the test pressure shall be increased in steps of approximately one-tenth of the test pressure until the required test pressure is reached. The test pressure should be held for a minimum of ten minutes. The pressure shall be reduced to a value equal to four-fifths of the test pressure and held for a time sufficient to permit complete inspection of the vessel. The visual inspection will be augmented with a half-hour or more gas pressure drop test and Snoop checking as may be required. All observations will be carefully and chronologically recorded in a logbook expressly for that purpose.

4. Should any sign of vessel failure or distortion be observed the test is terminated immediately by reducing the pressure to one atmosphere. A final disposition for the vessel will be arranged with the appropriate authorities.

5. Upon successful completion of the test the pressure is slowly reduced to atmospheric pressure, the test stand and source secured, and the pressure test precautions relaxed and signs removed.

\section{SAFETY}

The "Technical Appendix to Pressure Vessel Testing", Fermilab safety manual, 5034TA, is the appropriate and governing document. The salient points will be repeated here for continuity of context, but no attempt is made to provide another authority. Read 5034TA, attached.

The test requires a Pressure Testing Permit, see the last page of the TA, 5034TA-6, it is the permit application. It must be signed by the Test Coordinator (Kelly Dixon), Safety Officer (Bill Freeman), and the Division Head (Peter Garbincius). The test must be witnessed by the Safety Officier or his designee; a duly authorized Safety representative must be present for the test. Rick Luther, who has been directing the closure of the vessel and dealing with the construction crew, will coordinate this note with the requirements of the CBI NACON ASME Pressure Vessel Code inspector. Any modifications arising from those discussions will be made a part of this Procedure and be subject to approval by the Fermilab Safety office.

This test and procedure will be communicated to the DO Cryogenic Safety committee, but pressure testing is a Safety Office function and need not be approved by the Cryogenic Safety comnittee. 
Fermilab

EXHIBIT B

Pressure Testing Permit*
Date: $10 \mathrm{Jal} / 90$

Pneumatic

Maximum Allowable Working Pressure: $29,36 \mathrm{psig}$
Type of Test:

Test Pressure:
Hydrostatic psis

Items to be Tested:

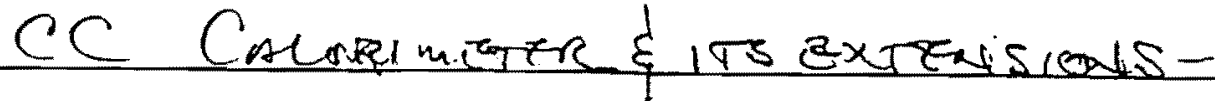

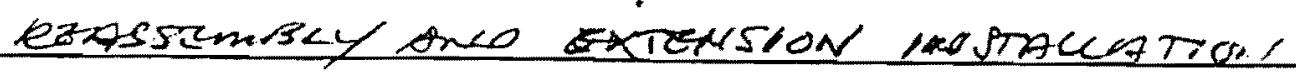

Location of Test: DAB Clean Revers

Date and Time:

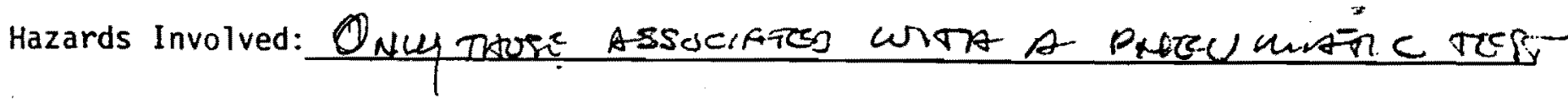

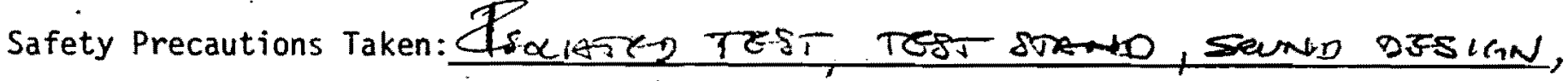

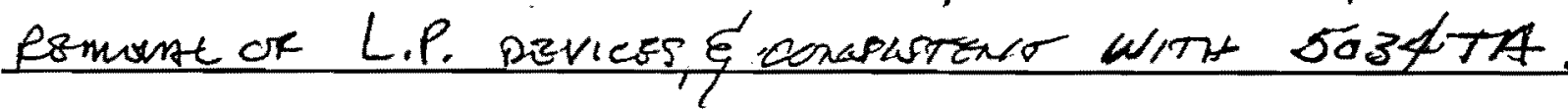

Special Conditions or Requirements: TEST must BS MADe WATA VAcech

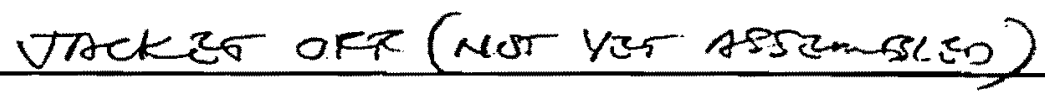

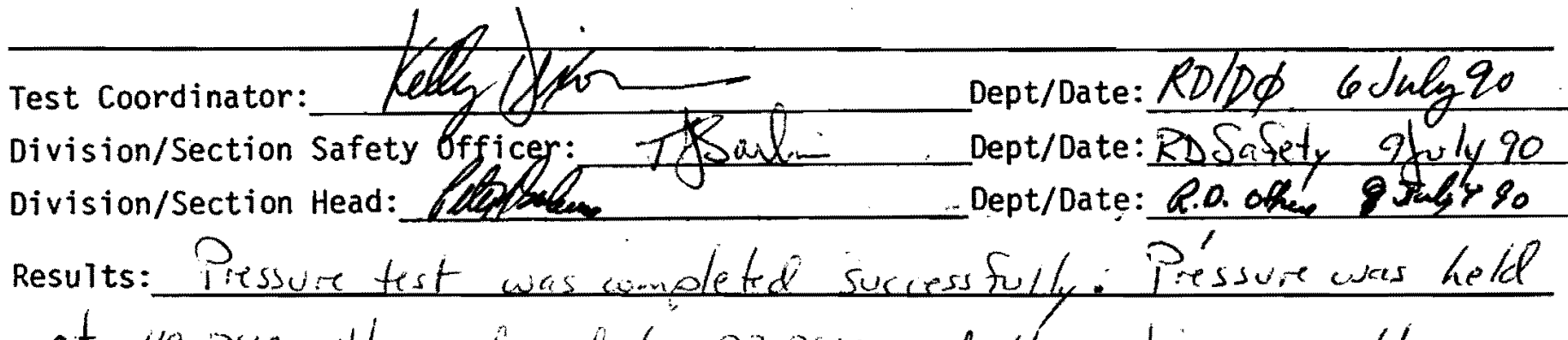
at 40 p sig, then reduced to 32 psia and the entries a seenbly was leak checked. One variation fou the original procedure was the installotiso of a TV coma ! monitor to remotely view the pressure gage un the vessel in the clean room.

Witness:

Soulemi

(Safety Officer or Designed) Dept/Date: 10 July 90

*Must be signed by division/section safety officer and division head prior to conducting test. It is the responsibility of the test coordinator to obtain signatures.

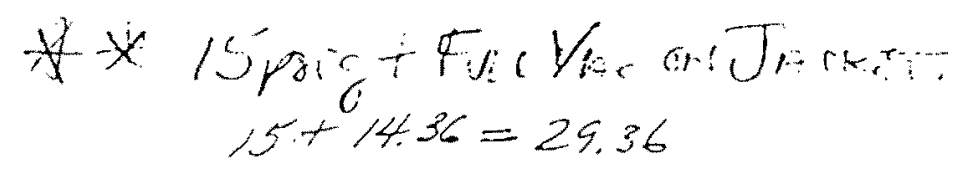

$5034 \times A-6$
$6 / 86$ 


\section{July 9, 1990 \\ CC Pressure Test Check List}

$\checkmark$ Check 0-ring groove requirement for signal box, relief port flanges

Make sealing provisions for above flanges

$\checkmark$ Hydrostatically test 4" Marmon and KF50 flange/cap ass'ys to 60 psi

$\checkmark$ Install pressurization field piping at outside cryobridge

Install female VCO fittings at pump \#90 trap

$\checkmark$ Install pressure indicator on top of vessel

$\checkmark$ Install transducer, chart recorder and associated wiring if available

$\checkmark$ Perform leak analyses using RGA and HMSLD

$\angle$ Call TJ Sarlina to confirm testing time

Break vacuum and perform ROR until 2PM, then bring vacuum up the rest of the way to $1 \mathrm{~atm}$

$\simeq$ Regenerate cold traps if manpower is available

$\checkmark$ Remove pirani gage on top of vessel and plug

$\checkmark$ Remove rupture disc assembly and install blind flange

- Remove relief valve port vacuum hose and install blind flange

Remove cryopump gate valve and the pump if necessary, install blind flange.

Remove PV215A and install KF50 cap and clamp

$\mathcal{L}$ Remove Welch pump vacuum hose at Marmon flange and install cap 
and clamp

_ Using a second party, check all bolts on blind fanges for tightness

_ Replace 10 psi relief with 44 psi one

Place warning signs at building entryways, ensure non-essential personnel has been evacuated 


\section{Pressure Test}

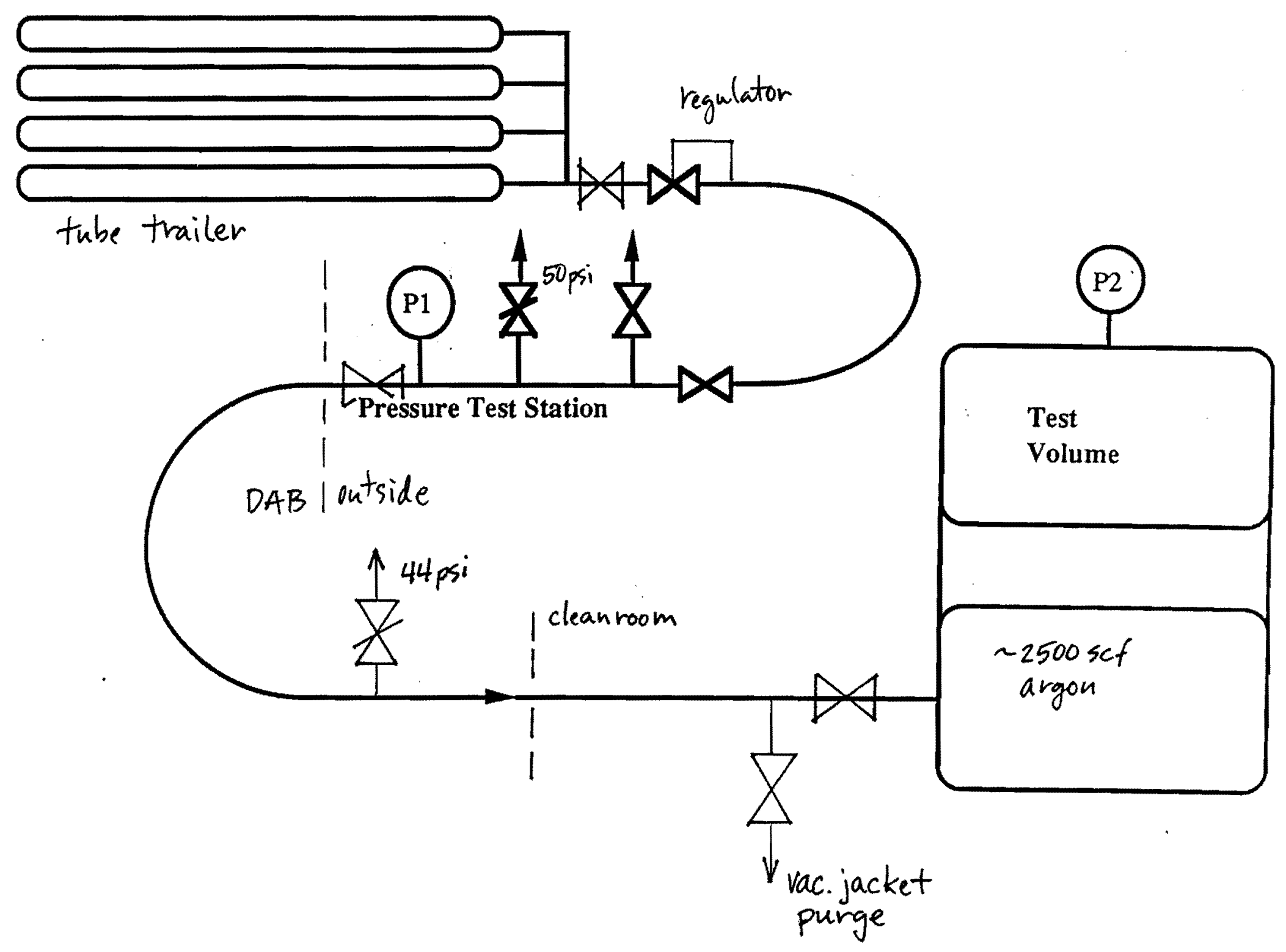

